\title{
Hybrid Membranes of Polyamide Applied in Treatment of Waste Water
}

\author{
Keila Machado de Medeiros ${ }^{a *}$, Edcleide Maria Araújo ${ }^{a}$, Hélio de Lucena Lira ${ }^{a}$, Diego de Farias
}

\author{
Lima ${ }^{b}$, Carlos Antônio Pereira de Lima
}

\author{
${ }^{a}$ Departamento de Engenharia de Materiais, Universidade Federal de Campina Grande - UFCG, Av. \\ Aprígio Veloso, 882, 58429-140, Campina Grande, PB, Brasil \\ ${ }^{b}$ Departamento de Engenharia Sanitária e Ambiental, Universidade Estadual da Paraíba - UEPB, Av. \\ Baraúnas, 351, 58429-500, Campina Grande, PB, Brasil
}

Received: March 23, 2016; Revised: September 06, 2016; Accepted: December 13, 2016

\begin{abstract}
In this work, it was prepared hybrid membranes of polyamide6 (PA6) with montmorillonite (MMT) and porogenic agent $\left(\mathrm{CaCl}_{2}\right)$. The hybrid membranes with $\mathrm{CaCl}_{2}$ were characterized by $\mathrm{X}$-ray diffraction (XRD), Fourier transform infrared spectroscopy (FTIR), differential scanning calorimetry (DSC), scanning electron microscopy (SEM), porosimetry by mercury intrusion (PMI), flux measurements and rejection. By means of X-ray diffraction, it was revealed that the hybrid membranes with $\mathrm{CaCl}_{2}$ have an exfoliated and/or partially exfoliated structure. For FTIR and DSC of hybrid membranes with $\mathrm{CaCl}_{2}$, it was found that the spectra and the crystalline melting temperature remained virtually unchanged compared to PA6 membrane. From the SEM images, it was observed that the addition of the MMT and the $\mathrm{CaCl}_{2}$ in the membrane of PA6 caused an increase in the amount of pores the surface and cross section of these membranes. By PMI, it was observed that the presence of $\mathrm{MMT}$ and $\mathrm{CaCl}_{2}$ in the membrane caused an increase in the average diameters of pores. The water-oil separation tests, indicated a significant reduction of oil in the permeate, allowing treatment of wastewater contaminated with oil.
\end{abstract}

Keywords: membranes, phase inversion, polyamide, porogenic agent

\section{Introduction}

From the beginning of the 70 s, classical separation processes such as distillation, filtration, adsorption, ion exchange, centrifugation, solvent extraction, crystallization and others, are substituted by a new class of processes called membranes separation processes (MSP) by using synthetic membranes as selective barriers ${ }^{1}$.

The porous synthetic membranes have pores of various sizes. These pores are responsible for all the properties that make the membranes useful in various applications, to separate particles and to fractionate molecules of different molecular weights ${ }^{2}$.

Water treatment is a crucial field closely related to environmental, economic, and social issues. Several water sources for our daily lives and industries typically contain oil, which has become the most common pollutant worldwide. In recent years, it is possible to find a large amount of research work about membranes for the treatment of oily wastewater in the literature, not only in experimental but also in theoretical terms ${ }^{3-7}$.

One of the major problems of the industries is the treatment of the effluent before being discharged in the environment or in a public sewage system. A large portion of this effluent is composed of oil in water emulsions ${ }^{8,9}$. The MSP are relatively simple and easy to operate, presents low consume energy and produces

* e-mail: keilamachadodemedeiros@gmail.com an effluent with good quality, facilitating reuse in the industrial process. These processes are presented as an alternative for the treatment of oily waste, mainly in the form of stable emulsions ${ }^{1,2}$.

Scholars reported the existence of several studies using MSP for the treatment of oily waste, including in the form of stable emulsions, most focusing on the use of ultrafiltration (UF) and microfiltration (MF) membranes in rejection of the oil droplets. In this study the drops of oil are completely rejected and the continuous phase is permeated ${ }^{9-11}$.

The phase inversion method is used to obtain polymeric membranes which are produced by precipitation from a polymer solution, allowing morphological modification from changes made in the parameters used during the membranes preparation ${ }^{12}$.

The synthetic polymers most widely used in the preparation of membranes are polyamide, polysulfone, polyacrylonitrile, polycarbonate, polyetherimide, poly (vinylidene fluoride), among others. Membranes prepared from these polymers have improved chemical, thermal and mechanical resistance compared with traditional polymers. In addition, they exhibit good resistance to chlorinated compounds (despite the low resistance to mechanical compression) and can be used with non-aqueous solvents ${ }^{13,14}$.

Polyamides are materials of high tensile strength, abrasion and fatigue resistance, low friction coefficient and good toughness. These properties were improved by the nanocomposite made with this polymer when compared to pure polymer ${ }^{15}$. 
Polyamide membranes offer the advantage of being a hydrophilic material, and for this reason do not require a wetting agent and are used in applications microfiltration and reverse osmosis ${ }^{16-21}$.

The combination of materials and processing allowed obtaining hybrids with special properties that do not exist in the original material. These properties depend on many factors, including the aspect ratio of the load, degree of dispersion, orientation of the load in the matrix and adhesion in load-matrix interface ${ }^{22-26}$.

The addition of nanoparticles of inorganics salts in hybrid materials provides significant changes in the morphological structure of the membranes. Furthermore, the use of these additives gives a wide applicability ranging from microfiltration to reverse osmosis ${ }^{27}$. This work examined the feasibility of the hybrid flat membranes with the addition of an inorganic salt for use in the treatment of wastewater.

\section{Experimental}

\subsection{Materials}

For this study, it was used the following materials: montmorillonite (MMT) Brasgel PA supplied by Bentonit União Nordeste (BUN), located in Campina Grande-PB/ Brazil. The polymer matrix used was the polyamide6 (PA6), named Technyl C216 and supplied by Rhodia, São Paulo - SP, Brazil. The formic acid manufactured by Vetec/ SP, Brazil, was used as solvent to dissolve the polymeric matrix. It was used calcium chloride dihydrate $\left(\mathrm{CaCl}_{2} \cdot 2 \mathrm{H}_{2} \mathrm{O}\right) \mathrm{PA}$ as an additive, with average molar mass of $147.01 \mathrm{~g} \cdot \mathrm{mol}^{-1}$, manufactured by Vetec/SP, Brazil.

\subsection{Preparation of hybrid materials}

The hybrid materials were prepared by the melt intercalation method in high speed homogenizer, $\mathrm{MH}-50 \mathrm{H}$ model of the brand MH Equipment. Before starting preparation, PA6 was dried in a circulating air oven for two hours, at $80^{\circ} \mathrm{C}$ and, subsequently remained in a vacuum oven, at $80^{\circ} \mathrm{C}$ for $48 \mathrm{~h}$. Then, the hybrid materials were prepared with 1, 3 and $5 \%$ $\mathrm{w} / \mathrm{w}$ of MMT. The procedure for mixing the hybrid materials were as follows: approximately $40 \mathrm{~g}$ of pure polyamide was placed in the chamber of the $\mathrm{MH}-50 \mathrm{H}$ homogenizer and the equipment was turned on for 1 minute, under these conditions the pure polyamide is melted by friction. Then, the MMT was placed and, the equipment was turned on again for 5 seconds. After, the pure polyamide or hybrid material was removed and, then crushed in a knife mill.

\subsection{Preparation of polymeric and hybrid membranes}

The pure PA6 or hybrid material with $1,3,5 \% \mathrm{w} / \mathrm{w}$ of MMT was dissolved in formic acid for a fixed time of 24 hours and added $10 \% \mathrm{w} / \mathrm{w}$ of $\mathrm{CaCl}_{2}$ to obtain a dispersion for the preparation of membranes, using the phase inversion technique by immersion precipitation. These dispersions were spread by means of glass rods with spacing of approximately $0.2 \mathrm{~mm}$ on glass plates and remained for a time of 300 seconds exposure in the atmosphere before the precipitation in a bath. This time of exposure of the dispersions before precipitation was suitable for obtaining flat microporous selective barriers. After, the dispersions were immersed in a non-solvent bath (with distilled water and room temperature). The formed membranes remained in the bath until its complete precipitation. Afterwards, the membranes were washed with distilled water and kept in a aqueous solution with $20 \% \mathrm{w} / \mathrm{w}$ of glycerin. The membranes were stored in a solution with glycerin to prevent pore collapse, and before being subjected to the permeability test, they were washed with distilled water to eliminate the glycerin.

\subsection{Characterizations of polymeric and hybrid membranes}

The polymeric and hybrid membranes were characterized by X-ray diffraction (XRD), using a Shimadzu XRD 6000 equipment, with $\lambda=1.541 \AA$, operating at $40 \mathrm{kV}$ and $30 \mathrm{~mA}$ and scanning angle from 1.5 to $30^{\circ}$. The analysis of Fourier transform infrared spectroscopy (FTIR) was performed on a Perkin-Elmer Spectrum 400 spectrometer with scan from 4000 to $650 \mathrm{~cm}^{-1}$. The membranes were characterized by Differential Scanning Calorimetry (DSC) on a Shimadzu DSC-50 equipment, from room temperature to $300{ }^{\circ} \mathrm{C}$ at a heating rate of $10^{\circ} \mathrm{C} \cdot \mathrm{min}^{-1}$ and under nitrogen atmosphere. The images from scanning electron microscopy were obtained in SSX 550 Superscan - Shimadzu equipment. For analysis of the cross section, the samples were fractured in liquid nitrogen to prevent a plastic deformation. The membranes were coated with gold. The porosity of the membranes was estimated by the mercury porosimeter Altopore IV, model 9500 of Micromeritics. All membranes were characterized in the form of thin films.

\subsection{Water permeability and oil retention}

For the tests of flux measurements with distilled water and water-in-oil emulsion, it was used a dead end filtration system in a cell with $13.0 \mathrm{~cm}^{2}$ of effective area. The membranes were submitted to permeation tests at 1.0 bar pressure. The membrane performance was evaluated by the permeate flux and selectivity with an emulsion of oil/water present in the feed solution at the concentrations of 50, 100 and $200 \mathrm{mg} . \mathrm{L}^{-1}$ and presenting oil droplets with diameters varying from 3 to $8 \mu \mathrm{m}$, as commonly used in microfiltration processes ${ }^{28}$.

The selectivity of the membranes was estimated by the rejection coefficient $(\mathrm{R} \%)$, calculated based on the ratio of 
the concentrations of oil in the permeate $\left(\mathrm{C}_{\mathrm{p}}\right)$ and the power $\left(\mathrm{C}_{0}\right)$ expressed by Equation 1:

$$
R(\%)=\left[\frac{\left(C_{0}-C_{P}\right)}{C_{0}}\right] \times 100
$$

\section{Results and discussion}

Figure 1 illustrates the results from X-ray diffraction of pure PA6 membranes and the hybrid materials with 1, 3, 5\% $\mathrm{w} / \mathrm{w}$ of MMT, adding $10 \% \mathrm{w} / \mathrm{w}$ of $\mathrm{CaCl}_{2}$.

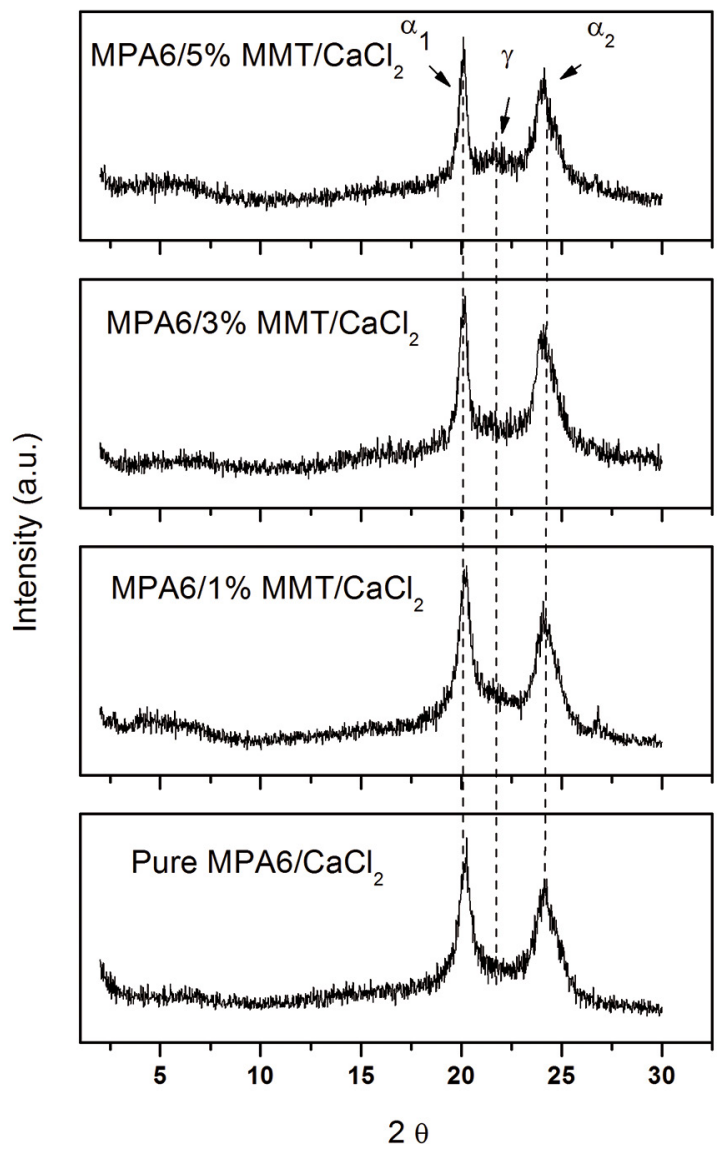

Figure 1. XRD diffraction curves of pure PA6 membranes and their hybrids 1,3 and $5 \% \mathrm{w} / \mathrm{w}$ of MMT, adding $10 \% \mathrm{w} / \mathrm{w}$ of $\mathrm{CaCl}_{2}$.

In Figure 1 it was observed the presence of two peaks at $20^{\circ}$ and $24^{\circ}$, for all compositions (PA6 pure and hybrid materials), which can be attributed to the formation of crystalline phase characteristic of polyamides, called phase $\alpha_{1}$ and $\alpha_{2}$ and related to the crystal diffraction planes (100) and $(002) /(202)$, respectively ${ }^{24}$. Polyamides are semicrystalline polymers and the presence of peak broadening indicates the existence of amorphous regions. Furthermore, the introduction of clay, regardless of the amount, changes slightly the shape and intensity of the peaks at $20^{\circ}$ and $24^{\circ}$ of the polyamide $6^{30-35}$.

It was found that the addition of $5 \% \mathrm{w} / \mathrm{w}$ of MMT in PA6, cause the appearance of the new reflection at $2 \theta=$ $21.8^{\circ}$ of the crystalline plan (001), which can be attributed to phase $\gamma$ (gamma) of PA6 $6^{36,37}$. The addition of $10 \% \mathrm{w} / \mathrm{w}$ of $\mathrm{CaCl}_{2}$ in the solution of membrane preparation did not cause significant changes with regard to the crystalline behavior and the main crystalline phase is $\alpha$, as illustrated by the X-ray diffraction curve of pure PA6 membranes and their hybrids.

The results of FTIR analysis of the pure PA6 membranes and their hybrids $1,3,5 \% \mathrm{w} / \mathrm{w}$ of MMT, adding $\mathrm{CaCl}_{2}$ as additive, can be seen in Figure 2 .

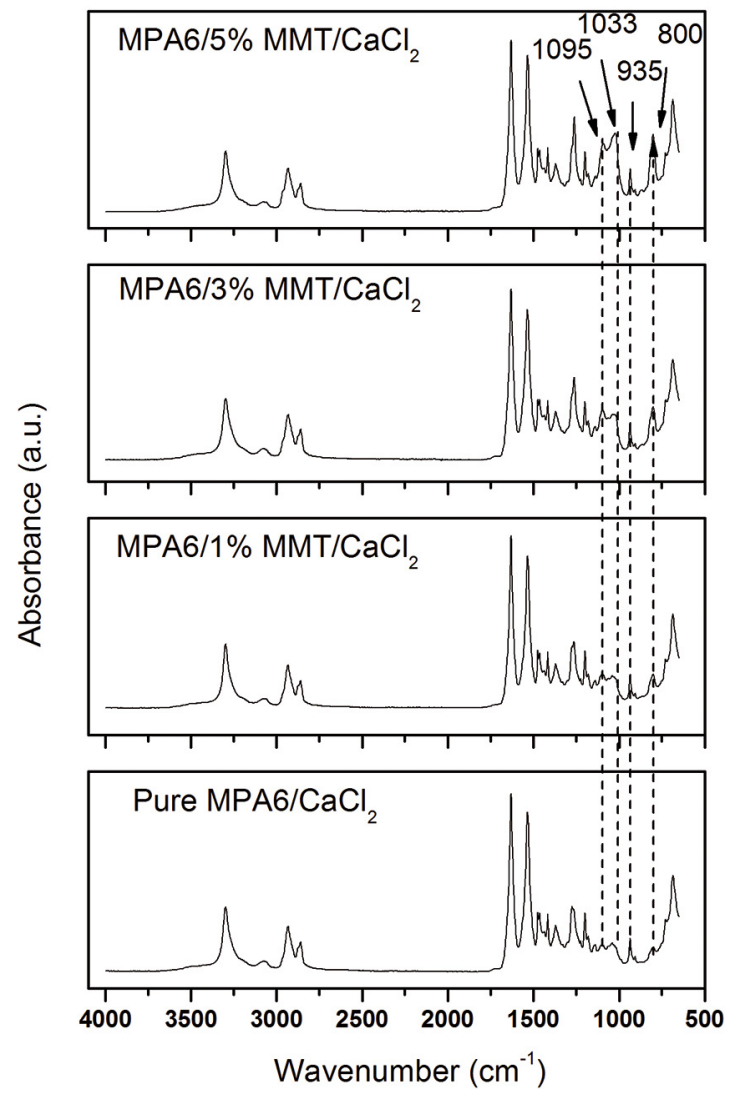

Figure 2. FTIR spectra of pure PA6 membranes and their hybrids 1,3 and $5 \% \mathrm{w} / \mathrm{w}$ of MMT, adding $10 \% \mathrm{w} / \mathrm{w}$ of $\mathrm{CaCl}_{2}$.

From Figure 2, it is noted that the general profile of FTIR spectra of the PA6 remained virtually unchanged, except for a small increase in the intensity of the peaks at wavelengths of 800,1033 and $1095 \mathrm{~cm}^{-1}$. These peaks can probably be related to the stretch vibration of the $\mathrm{Si}-\mathrm{O}-\mathrm{Si}$ group of the clay, since the contributions of PA6 in this particular area are very small. In addition, it was noticed a slight increase in the intensity of these peaks, which can be related to the increase in clay content, used in the preparation of hybrid membranes $^{38-42}$.

Also in Figure 2, it was observed typical characteristic bands of formic acid: a broadband at $3300 \mathrm{~cm}^{-1}$, related to the axial deformation of the O-H group; at 2940 and 2860 $\mathrm{cm}^{-1}$ there are bands related to axial strain of $\mathrm{C}-\mathrm{H}$ group, which is superimposed with the band of $\mathrm{O}-\mathrm{H}$ group; and at 
$1640 \mathrm{~cm}^{-1}$, there is the axial deformation of the $\mathrm{C}=\mathrm{O}$ group; the region of $1420 \mathrm{~cm}^{-1}$ is in agreement with the angular deformation of the $\mathrm{C}-\mathrm{O}-\mathrm{H}$ group; at $1256 \mathrm{~cm}^{-1}$ there is a band related to the axial strain of the $\mathrm{C}-\mathrm{O}$ group and also involves interactions with $\mathrm{C}-\mathrm{O}-\mathrm{H}$ group. However, these bands are not associated only with the formic acid used in preparing the membranes, but also are superimposed to the bands inherent of the PA $6{ }^{43}$. In the solution preparation step, a chemical reaction occurs between the -OH group of formic acid $(\mathrm{H}-\mathrm{COOH})$ and $\mathrm{Cl}^{-}$ion from $\mathrm{CaCl}_{2}$, promoting the formation of the chloride acid $(\mathrm{H}-\mathrm{COCl})$ in the solution ${ }^{44}$. In this way, occurs an increase in the intensity of a band at $935 \mathrm{~cm}^{-1}$, which can be related to angular deformation of the O-H group from formic acid, produced in the step of solvent exchanging by the non-solvent, specific to the reaction between the chloride acid and water ${ }^{45}$.

Table 1 shows the melting temperature $\left(\mathrm{T}_{\mathrm{m}}\right)$, melting enthalpy $\left(\Delta \mathrm{H}_{\mathrm{F}}\right)$ and degree of crystallinity $\left(\mathrm{X}_{\mathrm{c}}\right)$ for pure PA6 membranes and their hybrids $1,3,5 \% \mathrm{w} / \mathrm{w}$ of MMT, adding $10 \% \mathrm{w} / \mathrm{w}$ of $\mathrm{CaCl}_{2}$. For all the analyzed membranes, there are two endothermic peaks corresponding to the two crystalline phases existing, in approximately, $220^{\circ} \mathrm{C}$ related to the $\alpha$ phase and in $210{ }^{\circ} \mathrm{C}$ related to the $\gamma$ phase. The adding of clay improves the barrier properties of the films, however induces the appearance of $\gamma$ phase ${ }^{46-49}$.

In Table 1, there are variations in the degree of crystallinity of the nanocomposite membranes when compared with the membrane PA6. Probably, the presence of the clay crystalline behavior altered of PA6. However, when small percentages of clay are added to polymer matrices, the degree of crystallinity $\mathrm{Xc}$, increases the nanocomposite which may demonstrate a nucleating effect of the clay $^{34,35,49}$.

The SEM images of the top surface and cross section of pure PA6 membranes and their hybrids $1,3,5 \% \mathrm{w} / \mathrm{w}$ of MMT, adding $10 \% \mathrm{w} / \mathrm{w} \mathrm{CaCl}_{2}$, are shown in figures from 3 to 6 . In all SEM images it was observed asymmetric microporous membranes with a selective layer (filter skin) on the top and a porous layer on the bottom. In cross section, it is still possible to observe a variation in pore size throughout its thickness, with pores of spherical shape and evenly distributed. This difference in morphology on the cross section of the membrane is responsible for the permeability and selectivity of the membrane $e^{50,51}$.

The addition of $10 \%$ of $\mathrm{CaCl}_{2}$ in the preparation of pure PA6 membrane caused an increase in the amount of the pores and uniformity distribution of them on the surface and cross-section of these membranes. This behavior occurred due to the polar character and hydrophilicity of $\mathrm{CaCl}_{2}$ and also the physical-chemical interactions existing between $\mathrm{CaCl}_{2}$ and formic acid.

The exchange of the solvent by the non-solvent accelerates the solubility of $\mathrm{CaCl}_{2}$ during the formation of the membrane, promoting their solvation in formic acid and its hydration in water. Thus, the $\mathrm{CaCl}_{2}$ present in aqueous phase, accelerates the process of formation and distribution of pores on the membrane surface ${ }^{52}$. Furthermore, in preparation of the solution occurs the formation of the acid chloride, which in the exchange step of solvent by the non-solvent, reacts rapidly with the water.

The addition of $10 \% \mathrm{w} / \mathrm{w}$ of $\mathrm{CaCl}_{2}$ to prepare the hybrid membranes with $1,3,5 \% \mathrm{w} / \mathrm{w}$ of MMT, promoted a greater absorption of water vapor present in the atmosphere and favored the formation of pores in these regions where MMT and $\mathrm{CaCl}_{2}$ were dispersed on the surface of the membrane. In this step, the acid chloride reacts with water, contributing to the formation of a structure with a greater number and larger pores on the top surface ${ }^{53}$.

For all cross-sections analyzed it was observed the formation of macrovoids interconnected internally. The formation of these pores is attributed to the presence of a larger volume of trapped gases near the selective layer due to the concentration of PA6 ${ }^{54}$. It was also observed almost the same thickness of the selective layer and support of pure PA6 membrane $/ \mathrm{CaCl}_{2}$ compared to their hybrids 1, 3, 5\% w/w of MMT.

In Figure 7 is shown the pore size distribution characterized by the mercury intrusion porosimetry of pure PA6 membranes and their hybrids $1,3,5 \% \mathrm{w} / \mathrm{w}$ of MMT, adding $10 \% \mathrm{of} \mathrm{CaCl}_{2}$. It was observed a similar behavior of the curves for all membranes. The peak on the left side covers a range of diameters with an average of approximately $180 \mu \mathrm{m}$ which corresponds to the larger pores, which would be the porous support membrane ${ }^{55}$. It was noted that from this peaks is not possible to make an precise analysis of the pores in the support, since they have very large pore sizes above detection range mercury porosimetry. The region of the curve, which is the rightmost, is related to the pores on the selective layer of the membrane, which is responsible for the phase separation. It was observed that the presence of clay and of $\mathrm{CaCl}_{2}$ in the hybrid membranes had a direct influence on increasing pore size, in relation to the pure PA6 membrane. Furthermore, this increase was directly proportional to the increase in the percentage of clay.

Table 1. Values melting temperature $\left(\mathrm{T}_{\mathrm{m}}\right)$, melting enthalpy $\left(\Delta \mathrm{H}_{\mathrm{F}}\right)$ and crystallinity degree $\left(\mathrm{X}_{\mathrm{c}}\right)$ for the pure PA6 membranes and their hybrids 1,3 and $5 \% \mathrm{w} / \mathrm{w}$ of MMT, adding $10 \%$.

\begin{tabular}{lccc}
\hline Membranes & $\mathrm{Tm}_{\gamma} / \mathrm{Tm}_{\alpha}\left({ }^{\circ} \mathrm{C}\right)$ & $\Delta \mathrm{H}_{\mathrm{F}}\left(\mathrm{J} \cdot \mathrm{g}^{-1}\right)$ & $\mathrm{X}_{\mathrm{c}}(\%)$ \\
\hline Pure MPA6/CaCl & 22.3 \\
$\mathrm{MPA} 6 / 1 \% \mathrm{MMT} / \mathrm{CaCl}_{2}$ & $207.6 / 219.1$ & 41.9 & 22.5 \\
$\mathrm{MPA} 6 / 3 \% \mathrm{MMT} / \mathrm{CaCl}_{2}$ & $206.9 / 219,2$ & 41.8 & 22.4 \\
$\mathrm{MPA} 6 / 5 \% \mathrm{MMT} / \mathrm{CaCl}_{2}$ & $205.5 / 216.2$ & 40.9 & 24.1 \\
\hline
\end{tabular}

$\mathrm{T}_{\mathrm{m}}=$ Melting temperature; $\Delta \mathrm{H}_{\mathrm{F}}=$ Melting enthalpy; $\mathrm{X}_{\mathrm{c}}=$ Degree of crystallinity, $\Delta \mathrm{H}_{\mathrm{F}} / \Delta \mathrm{H}_{\mathrm{F} 100} \times 100 \% ; \Delta_{\mathrm{HF} 100}=$ Melting enthalpy of PA6 with $100 \%$ of crystallinity, $188 \mathrm{J.g}^{-128}$; The estimation of the degree of crystallinity was normalized in relation to the PA6. 

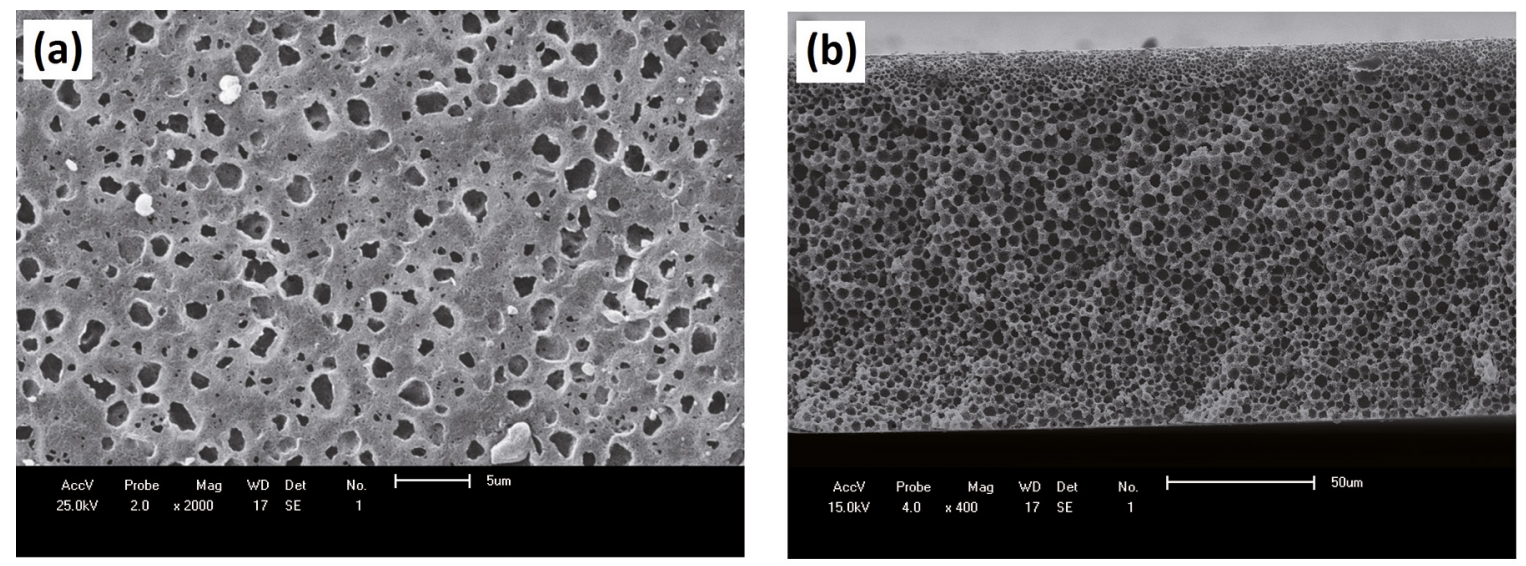

Figure 3. SEM images of pure $\mathrm{PA} 6 / \mathrm{CaCl}_{2}$ membrane: (a) top surface and (b) cross-section.
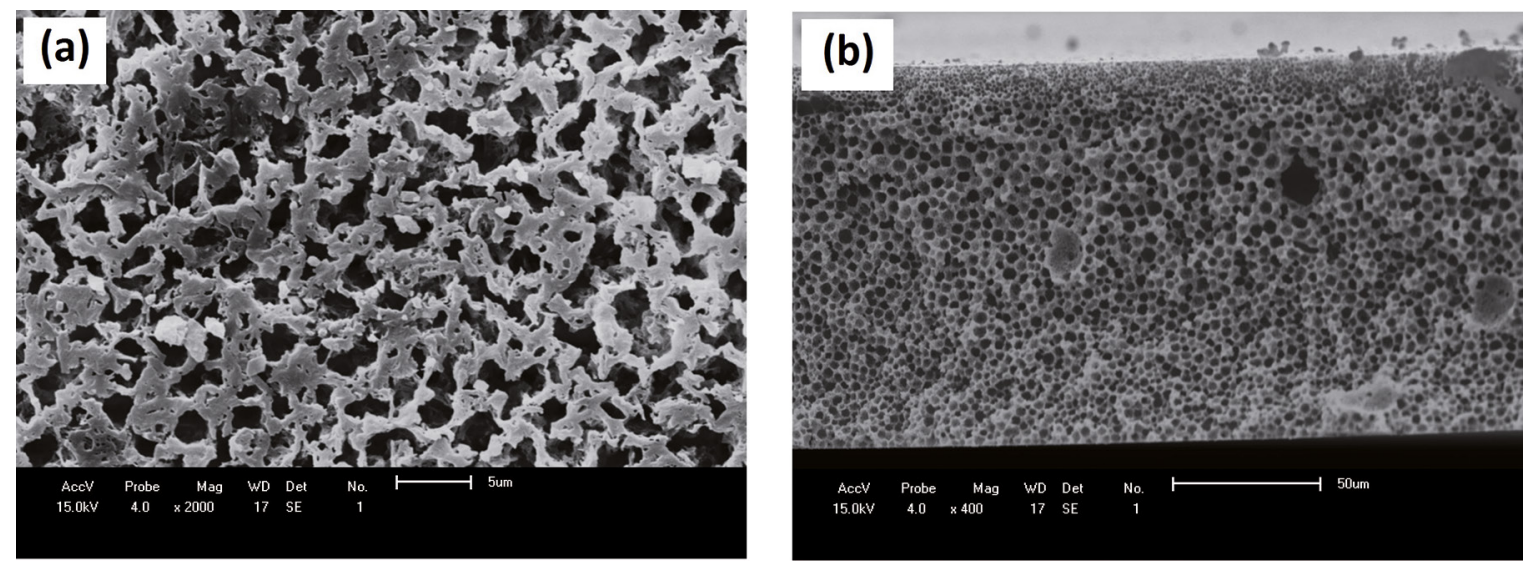

Figure 4. SEM images of $\mathrm{PA} 6 / 1 \% \mathrm{MMT} / \mathrm{CaCl}_{2}$ membrane: (a) top surface and (b) cross-section.
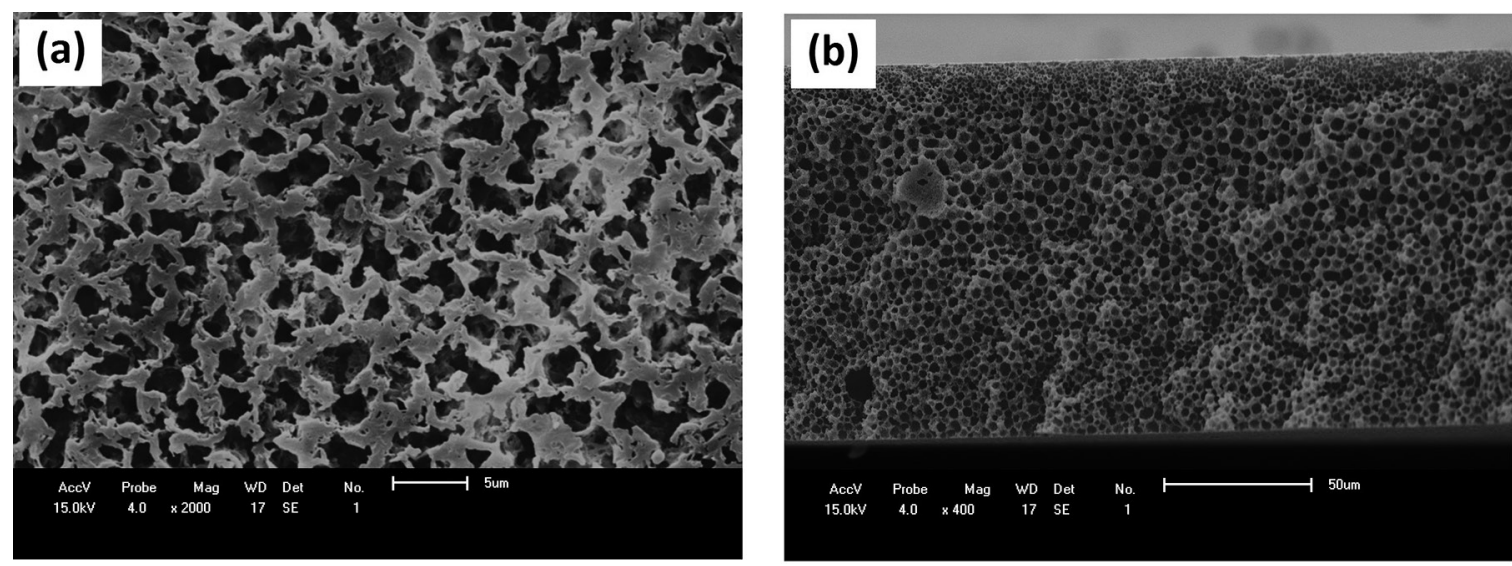

Figure 5. SEM images of $\mathrm{PA} 6 / 3 \% \mathrm{MMT} / \mathrm{CaCl}_{2}$ membrane: (a) top surface and (b) cross-section.

Also according to the curves of Figure 7, it is clear that pure PA6 membrane show an medium pore diameter of $1.0 \mu \mathrm{m}$, with low porosity of $29 \%$, enabling a significant reduction in the permeate flux. Therefore, the clay is incorporated into the membrane in order to act as porogenic agent promoting the increase of the pores and porosity of the obtained membrane.
Moreover, the hybrid membranes exhibited medium pore diameters in the range between 1.4 and $1.9 \mu \mathrm{m}$, with porosity ranging from $34-42 \%$. The values obtained for average pore diameters and porosity is appropriate for hybrid asymmetric microporous membranes, classifying for applications in microfiltration processes. 

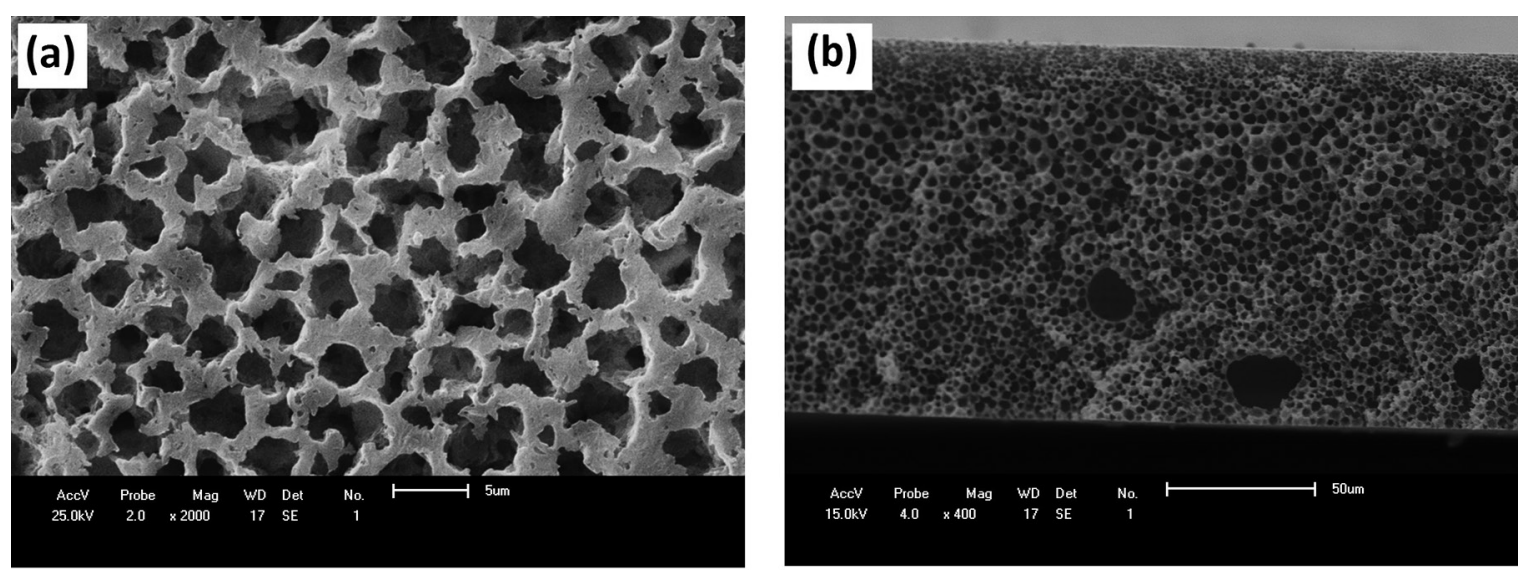

Figure 6. SEM images of $\mathrm{PA} 6 / 5 \% \mathrm{MMT} / \mathrm{CaCl}_{2}$ membrane: (a) top surface and (b) cross-section.

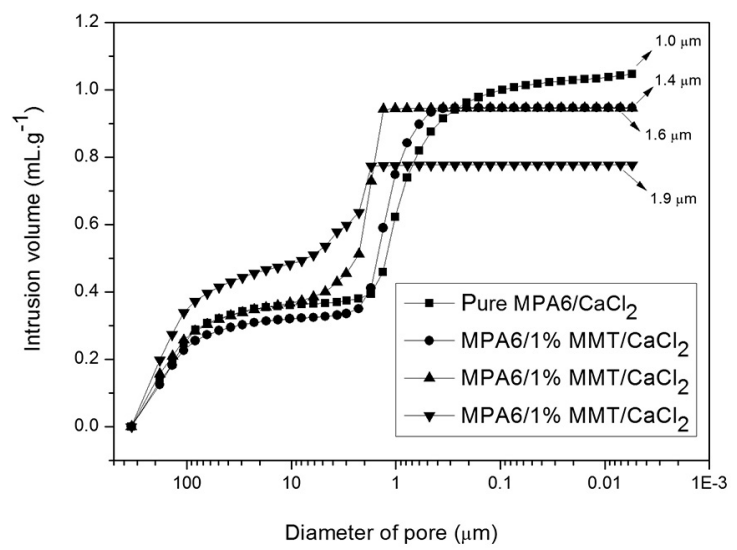

Figure 7. Pore size distribution for pure PA6 membranes and their hybrids with $1,3,5 \%$ of MMT, adding the additive $\mathrm{CaCl}_{2}$, by the mercury intrusion porosimetry.

Figure 8 shows the curves of the distilled water flux to the pure PA6 membrane and their hybrids $1,3,5 \% \mathrm{w} / \mathrm{w}$ of MMT, adding $10 \% \mathrm{w} / \mathrm{w}$ of $\mathrm{CaCl}_{2}$.

The permeate flux with distilled water to all membranes (Figure 8 ) initially presented a decrease and stabilized after 40 minutes. This decreases was due to a mechanical compaction promoted by the applied pressure. This process uses the pressure gradient as the driving force, and the permeate flux is directly proportional thereto. When it comes to a pure solvent and without interaction with the material of the membrane, the permeate flux for a given operating pressure should be constant, since the membrane present a mechanical stability. The PA6 is a hydrophilic polymer, facilitating the absorption of water by reducing the permeate flux rate and size of pores existing on the surface of these membranes $\mathrm{s}^{51,55-58}$.

The permeated flux (J) of the membranes for oil/ water emulsion was plotted in the relation to stabilized distilled water flux $\left(\mathrm{J}_{0}\right)$ and can be observed in Figure 9. It was observed for all membranes an initial decline and a stabilization of the permeated flux after a certain time. The

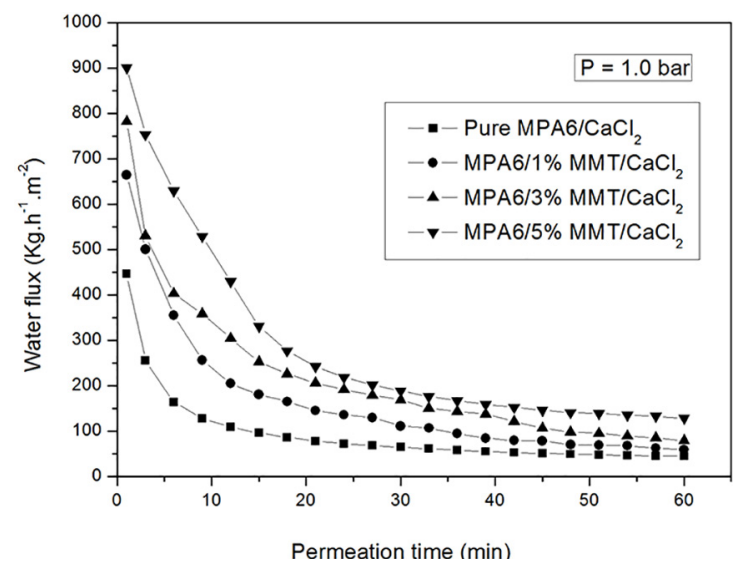

Figure 8. Distilled water flux curves for pure PA6 membranes and their hybrids with $1,3,5 \%$ of MMT, adding the additive $\mathrm{CaCl}_{2}$.

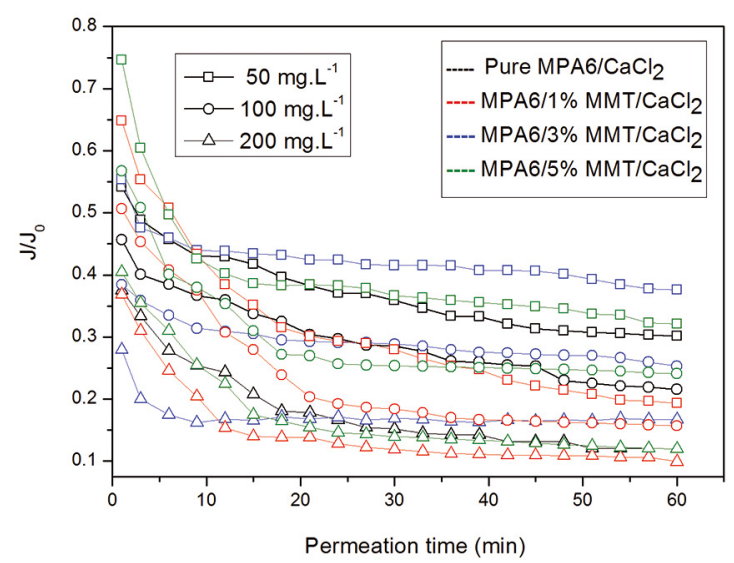

Figure 9. Influence of oil concentration (50, 100 and $\left.200 \mathrm{mg} . \mathrm{L}^{-1}\right)$ in the $\mathrm{J} / \mathrm{J}_{0}$ for pure PA 6 membranes and their hybrids with $1,3,5 \%$ of MMT, at 1.0 bar of pressure.

membranes with MMT (1, 3 and 5\%) presented higher $\mathrm{J} /$ $\mathrm{J}_{0}$ compared with PA6 pure membrane and this behavior is due to the formation of larger pores at surface of these membranes ${ }^{17,18,55}$. 
In general, $\mathrm{J} / \mathrm{J}_{0}$ tends to be lower when using high concentration emulsions. The increase in oil concentration provides clogging of the pores of the membranes and also contributes to a concentration polarization on the membrane surface, leading to a decrease in the $\mathrm{J} / \mathrm{J}_{0}{ }^{19,20}$.

Table 2 shows the oil concentration in the permeate $\left(\mathrm{C}_{\mathrm{P}}\right)$, in the feed suspension $\left(\mathrm{C}_{0}\right)$ and the rejection coefficient, using synthetic emulsion, for the pure PA6 membranes and their hybrids $1,3,5 \% \mathrm{w} / \mathrm{w}$ of MMT, adding $10 \% \mathrm{w} / \mathrm{w}$ of $\mathrm{CaCl}_{2}$.

Table 2. The oil concentration in the feed suspension $\left(\mathrm{C}_{0}\right)$, in the permeate $\left(\mathrm{C}_{\mathrm{p}}\right)$ and the rejection coefficient for all membranes at a pressure of 1.0 bar using synthetic emulsion

\begin{tabular}{lccc}
\hline Membranes & $\begin{array}{c}\mathrm{C}_{0} \\
\left(\mathrm{mg.L}^{-1}\right)\end{array}$ & $\begin{array}{c}\mathrm{C}_{\mathrm{p}} \\
\left(\mathrm{mg.L} \mathrm{L}^{-1}\right)\end{array}$ & $\begin{array}{c}\text { Rejection } \\
\text { coefficient (\%) }\end{array}$ \\
\hline \multirow{2}{*}{ Pure MPA6/CaCl 2} & 50 & 11.4 & 77.2 \\
& 100 & 6.6 & 93.4 \\
& 200 & 3.6 & 98.2 \\
MPA6/1\% MMT/CaCl 2 & 50 & 15.7 & 68.6 \\
& 100 & 7.2 & 92.8 \\
MPA6/3\% MMT/CaCl 2 & 100 & 14.1 & 85.9 \\
& 200 & 7.5 & 96.3 \\
& 50 & 19.4 & 61.2 \\
MPA6/5\% MMT/CaCl 2 & 100 & 12.3 & 87.7 \\
& 200 & 8.7 & 95.7 \\
\hline
\end{tabular}

For all membranes the rejection coefficient was higher for the feed oil concentrations of 100 and $200 \mathrm{mg}$. $\mathrm{L}^{-1}$. These behavior can be explained by the mean droplet size dispersion of oil for 50 and $200 \mathrm{mg} . \mathrm{L}^{-1}$ of oil concentrations, and these sizes are in the range of the average pore size of the selective layer of the membranes ${ }^{57-59}$ (see Table 2). Also due to the formation of oil polarization concentration close to the membranes surface, leading to clogging and obstructing thus the passage of oil, mainly at the highest concentration (200 $\left.\mathrm{mg} \cdot \mathrm{L}^{-1}\right)$. The polarization concentration is inherent in any selective transport process and contributes to the formation of a layer of polarization which provides additional resistance to mass transfer of solvent through the membrane, causing a drop in the flux permeated ${ }^{60-62}$.

All the studied membranes in the separation process of oil/water emulsions at the concentrations (50, 100 and $200 \mathrm{mg} . \mathrm{L}^{-1}$ ) achieved a significant reduction of oil in the permeate, meeting the requirements set by the resolution 430 of the National Environment Council, in Brazil, which states that the content of oils and greases in water must have a maximum concentration of $20 \mathrm{mg} . \mathrm{L}^{-1}$ to be discarded in the environment ${ }^{63}$.

\section{Conclusions}

Hybrid membranes of polyamide6 (PA6) with 1,3 and 5\% of untreated clay (MMT) and addition of porogenic agent $\left(\mathrm{CaCl}_{2}\right)$ was prepared with success. The hybrid membranes presented crystalline phases $\alpha_{1}$ and $\alpha_{2}$ (alpha) feature of polyamide and an exfoliated and / or partially exfoliated structure. The infrared spectra of the hybrid membranes with $\mathrm{CaCl}_{2}$ remained unchanged, except for the slight increase in the intensity of the peaks at 800 , 935,1033 and $1095 \mathrm{~cm}^{-1}$, due to the octahedral layer and the vibration of the stretch of Si-O-Si group from clay. There was no change in the crystalline melting temperature of the hybrid membranes with $\mathrm{CaCl}_{2}$ when compared with pure PA6 membrane. From the SEM images it was observed that the addition of clay and $\mathrm{CaCl}_{2}$ in the membranes caused an increase in the amount of pores and in the distribution uniformity of them, on the surface and in cross-section of the membranes when compared with pure PA6 membrane. The presence of clay and additive in the membrane caused an increase in average pore diameters of the selective layer, in the range from 1.2 to $2.7 \mu \mathrm{m}$. In general, the permeate flux with distilled water in membranes decreases due to a swelling and/or compression of the membranes. The water-oil separation tests, with feed concentration from 50 to $200 \mathrm{mg} . \mathrm{L}^{-1}$ of oil in water, indicated a significant reduction of oil in the permeated with results below $20 \mathrm{mg} . \mathrm{L}^{-1}$, meeting the requirements set by the National Environment Council, in Brazil, and with potential for the treatment of wastewater contaminated with oil.

\section{Acknowledgements}

The authors thank to the Bentonit União Nordeste (BUN), to Rhodia/SP, to LabMat (Laboratory of Materials Engineering/CCT/UFCG), to $\mathrm{MCT} / \mathrm{CNPq}$, to FINEP, to CTBRASIL, to CTPETRO, to PETROBRAS, to CAPES/ PNPD and PRH-25/ANP for financial support.

\section{References}

1. Baker RW. Membrane Technology and Applications. $2^{\text {nd }}$ Ed. Hoboken: John Wiley \& Sons; 2004.

2. Mulder M. Basic Principles of Membrane Technology. $2^{\text {nd }}$ Ed. Dordrecht: Kluwer Academic Publishers; 1996.

3. Wang Z, Jiang X, Cheng X, Lau CH, Shao L. Mussel inspired hybrid coatings that transform membrane hydrophobicity into high hydrophilicity and underwater superoleophobicity for oil-in-water emulsion separation. ACS Applied Materials \& Interfaces. 2015;7(18):9534-9545.

4. Cheng XQ, Liu Y, Guo Z, Shao L. Nanofiltration membrane achieving dual resistance to fouling and chlorine for "green" separation of antibiotics. Journal of Membrane Science. 2015;493:156-166. 
5. Wang Z, Xu Y, Liu Y, Shao Y. A novel mussel-inspired strategy toward superhydrophobic surfaces for self-driven crude oil spill cleanup. Journal of Materials Chemistry A. 2015;3:12171-12178.

6. Wang ZX, Lau CH, Zhang NQ, Bai YP, Shao L. Mussel-inspired tailoring of membrane wettability for harsh water treatment. Journal of Materials Chemistry A. 2015;3:2650-2657.

7. Xu YC, Cheng XQ, Long J, Shao L. A novel monoamine modification strategy toward high-performance organic solvent nanofiltration (OSN) membrane for sustainable molecular separations. Journal of Membrane Science. 2016;497:77-89.

8. Geerken MJ, Groenendijk MNW, Lammertink RGH, Wessling M. Micro-fabricated metal nozzle plates used for water-in-oil and oil-in-water emulsification. Journal of Membrane Science. 2008;310(1-2):374-383.

9. Hong A, Fane AG, Burford R. Factors affecting membrane coalescence of stable oil-in-water emulsions. Journal of Membrane Science. 2003;222(1-2):19-39.

10. Srijaroonrat P, Julien E, Aurelle Y. Unstable secondary oil/water emulsion treatment using ultrafiltration: fouling control by backflushing. Journal of Membrane Science. 1999;159(1-2):11-20.

11. Khan AY, Talegaonkar S, Iqbal Z, Ahmed FJ, Khar RK. Multiple emulsions: an overview. Current Drug Delivery. 2006;3(4):429-443.

12. Leite AMD, Araújo EM, Medeiros VN, Paz RA, Lira HL. Comparative study of membranes PA6 and PA66/national clay nanocomposites. In: Hashim A, org. Advances In Nanocomposite Technology. Rijeka: InTech; 2011. p. 115-130.

13. Santos FRA, Borges CP, Fonseca FV. Polymeric Materials for Membrane Contactor Devices Applied to Water Treatment by Ozonation. Materials Research. 2015;18(5):1015-1022.

14. Habert AC, Borges CP, Nóbrega R. Processos de Separação por Membranas. $1^{\text {a }}$ ed. Rio de Janeiro: E-papers; 2006. 180 p.

15. Anadão P. Ciência e Tecnologia de Membranas. São Paulo: ArtLiber; 2010.

16. Lin DJ, Chang CL, Lee CK, Cheng LP. Fine structure and crystallinity of porous Nylon 66 membranes prepared by phase inversion in the water/formic acid/Nylon 66 system. European Polymer Journal. 2006;42(2):356-367.

17. Singh PS, Rao AP, Ray P, Bhattacharya A, Singh K, Saha NK, et al. Techniques for characterization of polyamide thin film composite membranes. Desalination. 2011;282:78-86.

18. Tsai TY, Lin WH, Lin YY, Hsu YC, Ray U, Lin YT, et al. Permeability property of Nylon 6 nanocomposite membranes with various clay minerals. Desalination. 2008;233(1-3):183-190.

19. Wu H, Tang B, Wu P. Optimizing polyamide thin film composite membrane covalently bonded with modified mesoporous silica nanoparticles. Journal of Membrane Science. 2013;428:341-348.

20. Xu J, Feng X, Gao C. Surface modification of thin-film-composite polyamide membranes for improved reverse osmosis performance. Journal of Membrane Science. 2011;370(1-2):116-123.

21. Huang L, McCutcheon JR. Hydrophilic nylon 6,6 nanofibers supported thin film composite membranes for engineered osmosis. Journal of Membrane Science. 2014;457:162-169.
22. Espeso J, Lozano AE, de la Campa JG, de Abajo J. Effect of substituents on the permeation properties of polyamide membranes. Journal of Membrane Science. 2006;280(1-2):659-665.

23. Cho JW, Paul DR. Nylon 6 nanocomposites by melt compounding. Polymer. 2001;42(3):1083-1094.

24. Choudalakis G, Gotsis AD. Permeability of polymer/clay nanocomposites: A review. European Polymer Journal. 2009;45(4):967-984.

25. Picard E, Gérard JF, Espuche E. Water transport properties of polyamide 6 based nanocomposites prepared by melt blending: On the importance of the clay dispersion state on the water transport properties at high water activity. Journal of Membrane Science. 2008;313(1-2):284-295.

26. García A, Eceolaza S, Iriarte M, Uriarte C, Etxeberria A. Barrier character improvement of an amorphous polyamide (Trogamid) by the addition of a nanoclay. Journal of Membrane Science. 2007;301(1-2):190-199.

27. Bulte AMW. Nylon 4,6 as membrane material: polymer crystallization during immersion precipitation. [Doctoral Thesis]. Twente: University of Twente; 1994.

28. Motta A, Borges C, Esquerre K, Kiperstok A. Oil Produced Water treatment for oil removal by an integration of coalescer bed and microfiltration membrane processes. Journal of Membrane Science. 2014;469:371-378.

29. Kohan IM, ed. Nylon Plastics Handbook. Munich, Vienna, New York: Hanser Gardner; 1995.

30. Bezerra EB, Leite AMD, Araújo EM, Melo TJA, Cunha CT, Maia LF. Influence of the Addition of Polypropylene and Compatibilizer in PA6 Membranes Obtained by Phase Inversion. Materials Science Forum. 2014;775-776:173-177.

31. Medeiros KM, Silva TRG, Morais DDS, Kojuch LR, Araújo EM, Lira HL. Study of Morphology Membrane of Polymeric Nanocomposites Obtained by Phases Inversion. Materials Science Forum. 2014;775-776:498-503.

32. Medeiros KM, Medeiros VN, Morais DDS, Kojuch LR, Araújo EM, Lira HL. Analysis of the Efficiency of Surface Treatment of Bentonite Clay for Application in Polymeric Membranes. Materials Science Forum. 2014;775-776:493-497.

33. Beatrice CAG, Santos CR, Branciforti MC, Bretas RES Nanocomposites of polyamide 6/residual monomer with organic-modified montmorillonite and their nanofibers produced by electrospinning. Materials Research. 2012;15(4):611-621.

34. Paz RA, Araújo EM, Pessan LA, Melo TJA, Leite AD, Medeiros VN. Evaluation of impact strength of polyamide $6 /$ bentonite clay nanocomposites. Materials Research. 2012;15(4):506-509.

35. Leite AMD, Araújo EM, Paz RA, Pereira OD, Lira HL, Ito EN. Structure and mechanical properties of polyamide 6/Brazilian clay nanocomposites. Materials Research. 2009;12(2):165-168.

36. Ferreira RSB, Pereira CHO, Paz RA, Leite AMD, Araújo EM, Lira HL. Influence of Processing Type in the Morphology of Membranes Obtained from PA6/MMT nanocomposites. Advances in Materials Science and Engineering. 2014;2014:659148. 
37. Maia LF, Leite AMD, Araújo EM, Lira HL, Paz RA. Spectroscopic and Diffractional Characteristics of Membranes and Polyamide 6/Regional Bentonite Clay Nanocomposites. Materials Science Forum. 2014;775-776:168-172.

38. Li J, Zuo Y, Cheng X, Yang W, Wang H, Li Y. Preparation and characterization of nano-hydroxyapatite/polyamide 66 composite GBR membrane with asymmetric porous structure. Journal Materials Science: Materials in Medicine. 2009;20:1031-1038.

39. Loo LS, Gleason KK. Investigation of polymer and nanoclay orientation distribution in nylon $6 /$ montmorillonite nanocomposite. Polymer. 2004;45(17):5933-5939.

40. Elzein T, Brogly M, Schultz J. Quantitative calculation of the orientation angles of adsorbed polyamides nanofilms. Polymer. 2003;44(13):3649-3660.

41. Elzein T, Brogly M, Schultz J. Cristallinity measurements of polyamides adsorbed as thin films. Polymer. 2002;43(17):48114822.

42. Zeni M, Riveros R, Souza JF, Mello K, Meireles C, Rodrigues Filho G. Morphologic analysis of porous polyamide 6,6 membranes prepared by phase inversion. Desalination. 2008;221(1-3):294-297.

43. Kwon YN, Hong S, Choi H, Tak T. Surface modification of a polyamide reverse osmosis membrane for chlorine resistance improvement. Journal of Membrane Science. 2012;415416:192-198.

44. McMurry J. Química Orgânica. Combo: Tradução da 7a Edição Norte-Americana. São Paulo: Cengage Learning; 2011.

45. Silverstein RM, Webster FX, Kiemle D. Spectrometric Identification of Organic Compounds. $7^{\text {th }}$ ed. Hoboken: John Wiley \& Sons; 2005.

46. Kojuch LR, Medeiros KM, Morais DDS, Araújo EM, Lira HL. Study of Nanocomposites of Polyamide 6.6/National Bentonite Clay. Materials Science Forum. 2012;727-728:894-898.

47. Guerrini LM, Branciforti MC, Canova T, Bretas RES. Electrospinning and characterization of polyamide 66 nanofibers with different molecular weights. Materials Research. 2009;12(2):181-190.

48. Sabard M, Gouanvé F, Espuche E, Fulchiron R, Seytre G, Fillot LA, et al. Influence of film processing conditions on the morphology of polyamide 6: Consequences on water and ethanol sorption properties. Journal of Membrane Science. 2012;415-416:670-680.

49. Leite AMD, Maia LF, Paz RA, Araújo EM, Lira HL. Thermal properties from membrane of polyamide 6/montmorillonite clay nanocomposites obtained by immersion precipitation method. Journal of Thermal Analysis and Calorimetry. 2009;97:577-580.

50. Nikkola J, Sievänen J, Raulio M, Wei J, Vuorinen J Tang CY. Surface modification of thin film composite polyamide membrane using atomic layer deposition method. Journal of Membrane Science. 2014;450:174-180.
51. Poletto P, Duarte J, Thürmer MB, Santos V, Zeni M. Characterization of Polyamide 66 membranes prepared by phase inversion using formic acid and hydrochloric acid such as solvents. Materials Research. 2011;14(4):547-551.

52. Don TM, Hsu YC, Tai HY, Fu E, Cheng LP. Preparation of bicontinuous macroporous polyamide copolymer membranes for cell culture. Journal of Membrane Science. 2012;415-416:784-792.

53. Kong C, Koushima A, Kamada T, Shintani T, Kanezashi M, Yoshioka T, et al. Enhanced performance of inorganic-polyamide nanocomposite membranes prepared by metal-alkoxide-assisted interfacial polymerization. Journal of Membrane Science. 2011;366(1-2):382-388.

54. Ma N, Wei J, Liao R, Tang CY. Zeolite-polyamide thin film nanocomposite membranes: Towards enhanced performance for forward osmosis. Journal of Membrane Science. 2012;405406:149-157.

55. Biron DS, Poletto P, Duarte J, Zeni M, Bergmann CP, Santos V. Preparation and Characterization of PA66/Alumina Composite Membrane. Materials Research. 2015;18(4):748-755.

56. Alsvik IL, Hägg MB. Preparation of thin film composite membranes with polyamide film in hydrophilic supports. Journal of Membrane Science. 2013;428:225-231.

57. Huang L, Bui NN, Meyering MT, Hamlin TJ, McCutcheon JR. Novel hydrophilic nylon 6,6 microfiltration membrane supported thin film composite membranes for engineered osmosis. Journal of Membrane Science. 2013;437:141-149.

58. Medeiros VN, Carvalho TC, Leite AMD, Araújo EM, Lira HL. Evaluation of the effect of clay in polyethersulfone membranes. Desalination and Water Treatment. 2015;56(13):3554-3560.

59. Kumar RV, Ghoshal AK, Pugazhenthi G. Elaboration of novel tubular ceramic membrane from inexpensive raw materials by extrusion method and its performance in microfiltration of synthetic oily wastewater treatment. Journal of Membrane Science. 2015;490:92-102.

60. Mueller J, Cen Y, Davis RH. Crossflow microfiltration of oily water. Journal of Membrane Science. 1997;129(2):221-235.

61. Chakrabarty B, Ghoshal AK, Purkait MK. Ultrafiltration of stable oil-in-water emulsion by polysulfone membrane. Journal of Membrane Science. 2008;325(1):427-437.

62. Kojuch LR, Medeiros KM, Araújo EM, Lira HL. Obtaining of Polyamide 6.6 Plane Membrane Application in Oil-Water Separation. Materials Science Forum. 2014;775-776:460-464.

63. Brasil. Ministério do Meio Ambiente. Conselho Nacional do Meio Ambiente. Resolução ${ }^{\circ} 430$, de 13 de maio de 2011. Dispõe sobre as condições e padrões de lançamento de efluentes. Brasília: Ministério do Meio Ambiente; 2011. Available from: <http:// www.mma.gov.br/port/conama/legiabre.cfm?codlegi=646>. Access in: 02/03/2016. 